IdeAs

Idées d'Amériques

$4 \mid 2013$

Crises et effets de crise dans les Amériques

\title{
Los perímetros americanos frente a la crisis y a la globalización
}

American blocs in the face of the crisis and globalization

Les périmètres Américains face à la crise et à la globalisation

Florence Pinot de Villechenon

(2) OpenEdition

Journals

Édition électronique

URL : https://journals.openedition.org/ideas/760

DOI : 10.4000/ideas.760

ISSN : 1950-5701

Éditeur

Institut des Amériques

Référence électronique

Florence Pinot de Villechenon, «Los perímetros americanos frente a la crisis y a la globalización », IdeAs [En ligne], 4 | 2013, mis en ligne le 14 octobre 2013, consulté le 20 octobre 2022. URL : http:// journals.openedition.org/ideas/760 ; DOI : https://doi.org/10.4000/ideas.760

Ce document a été généré automatiquement le 20 octobre 2022.

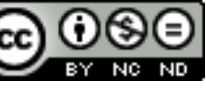

Creative Commons - Attribution - Pas d'Utilisation Commerciale - Pas de Modification 4.0 International - CC BY-NC-ND 4.0

https://creativecommons.org/licenses/by-nc-nd/4.0/ 


\section{Los perímetros americanos frente a la crisis y a la globalización}

American blocs in the face of the crisis and globalization

Les périmètres Américains face à la crise et à la globalisation

Florence Pinot de Villechenon

\section{NOTE DE L'ÉDITEUR}

Cet article est traduit du français par Marta Gómez

\section{Introduction}

1 El 15 de septiembre de 2008, el anuncio de la quiebra de Lehman Brothers hacía temblar a los mercados financieros y sembraba la alarma en todo el mundo. Lo que numerosos analistas coinciden en señalar como la mayor crisis del sistema capitalista desde 1929, de la que aún no se han evaluado todas las consecuencias, se ha producido - cabe recordar - en un contexto marcado por una fuerte expansión de los intercambios y un peso cada vez mayor de los países en desarrollo en la escena internacional. En efecto, dichos países dan muestra de una mayor participación no sólo en los flujos comerciales y financieros, sino también en la gestión de las grandes cuestiones contemporáneas:alimentación, medio ambiente, energía, ahorro, seguridad, solidaridad, migraciones, etc. En términos « institucionales », este hecho se traduce en el desplazamiento progresivo del centro de gravedad desde el viejo G8 al nuevo G20. Asimismo, cabe esperar que se produzcan otros cambios con respecto al sistema financiero y a las grandes organizaciones que rigen la vida internacional desde finales de la Segunda Guerra Mundial. 
2 Nuestro objetivo aquí es analizar cómo este nuevo entorno afecta el posicionamiento de los países latinoamericanos en el continente y condiciona su acercamiento. Para ello, nos basaremos en la noción de perímetro.

¿Qué entendemos por perímetro? En términos geométricos, un perímetro es una superficie, y también un contorno. El concepto se refiere al espacio trazado a partir de un punto preciso y es muy cercano a la noción de frontera : el espacio establecido es, por naturaleza, limitado ; una frontera lo separa, por tanto, del espacio colindante. La cuestión del centro o epicentro, por hablar en términos geológicos, es determinante, ya que el perímetro se traza a partir de dicho punto. Así sucede cuando se establece un perímetro de seguridad en una zona afectada por una catástrofe natural o cuando se define un perímetro de intervención para prestar socorro.

4 En un registro totalmente distinto, la contabilidad también recurre al concepto de perímetro : para las cuentas consolidadas de un grupo empresarial, por ejemplo, se exige la delimitación de un perímetro de consolidación y la construcción de las « fronteras contables » del grupo. En el ámbito de la defensa, un Estado diseña y despliega sus mecanismos de defensa en función de un perímetro de seguridad.

5 Ahora bien, el establecimiento de un perímetro, sobre todo en sentido figurado, está íntimamente ligado a las representaciones de los actores que gravitan en ese espacio y a su percepción de los retos, e incluso de las amenazas, que los rodean. El mundo animal nos da una ilustración muy precisa de ello : en el ruedo, el toro crea con sus cuernos un círculo dentro del cual siente la amenaza de la agresión. Los felinos y las aves también ofrecen numerosos ejemplos de perímetros delimitados con ayuda de ciertos órganos que se consideran determinantes para su seguridad e incluso para su supervivencia. En otro ámbito bien distinto, podemos hablar también de perímetro social para designar el entramado de relaciones que cualquier individuo o grupo puede desarrollar o mantener a través de herramientas como Facebook.

6 A su vez, la noción de «espacio» no es inmune a los cambios tecnológicos. Una disciplina como la geopolítica, tradicionalmente preocupada por el espacio físico o geográfico, ha introducido el concepto de « potencia a-territorial » en la que el dominio de las redes y del espacio virtual se convierte en un factor de supremacía en detrimento del espacio físico (Rosière, 2003 : 297).

7 Espacio en sentido propio, espacio en sentido figurado, desafíos, amenazas, representaciones... nociones todas ellas que, junto con el concepto de perímetro, son necesarias para comprender la evolución de las relaciones internacionales. Las relaciones internacionales se establecen entre actores que se convierten en interlocutores y cada uno construye su estrategia de diálogo (o de confrontación) en función de las representaciones que tiene del otro y en función del potencial que detecta en la relación.

8 Volviendo a los perímetros, hasta mediados del siglo xx los historiadores de las relaciones internacionales se han centrado en los actores y en los perímetros estatales. Sin embargo, la pérdida del monopolio de los Estados en estas relaciones y el rápido ascenso de actores no tradicionales (como la sociedad civil y las ONG) y de las redes (narcotraficantes, terroristas) han hecho que el concepto de perímetro estatal se torne insuficiente en la medida en que no abarca la totalidad de las relaciones internacionales. 
Dicha observación nos ha llevado, en estudios previos sobre las relaciones de cooperación ${ }^{1}$, a definir nociones complementarias. En efecto, en torno al tradicional perímetro estatal se observan dos fenómenos opuestos y concomitantes como son su fragmentación por un lado, y su expansión por otro, así como numerosas interacciones resultantes entre los diferentes perímetros.

Muy brevemente, la expansión del perímetro estatal tiene que ver con la construcción, desde mediados del siglo xx, de conjuntos supranacionales. Los Estados se han visto inducidos progresivamente a renunciar a la exclusividad en el tratamiento de numerosas cuestiones ligadas al comercio, la salud, los transportes, la energía, la formación, la investigación, etc., dando lugar a la instauración de lógicas intergubernamentales o supranacionales definidas por los diversos tratados de integración y/o de cooperación. En cuanto a la fragmentación, ésta es inseparable de las políticas de descentralización que en numerosos países obedecen al deseo de acercar la administración al ciudadano. En materia de cooperación internacional, esto se traduce en una creciente participación de las entidades territoriales en los programas de cooperación con el extranjero. Existen, por lo tanto, perímetros de cooperación internacional supraestatales, además de perímetros de cooperación internacional subestatales. Para los primeros, utilizamos un término equivalente: regional. En América Latina, su uso es muy frecuente desde la segunda mitad del siglo xx entre dirigentes políticos, economistas e investigadores, mientras que en francés el término «región» ha servido sobre todo para designar, en el pasado reciente, el nivel infraestatal, como señala Yves Lacoste ${ }^{2}$.

11 En cuanto a las representaciones, Yves Lacoste las define de esta manera:«(...) el conocimiento que se tiene de un dato material, considerado como objetivo, ya es una representación ». Lo que diferencia una representación de una idea es que, « sobre todo si es colectiva, tiene una función : describe, expresa una parte de la realidad, de forma vaga o precisa, deformada o exacta. Una representación es una construcción, un conjunto de ideas más o menos lógicas y coherentes ». Las representaciones están cargadas de sentido y pueden condicionar el planteamiento estratégico de los actores ${ }^{3}$.

Perímetros y representaciones están, por tanto, íntimamente relacionados. Un perímetro conserva su pertinencia desde el momento en que las representaciones con las que se vincula siguen activas. De ahí nuestras preguntas : la noción de perímetro regional, ¿ es funcional a la hora de analizar la realidad latinoamericana actual ? ¿ Es el nivel regional un buen nivel de análisis político? (Girault, 2009) ¿Cuáles son las representaciones que lo sustentan? En segundo lugar, ¿ estamos asistiendo a un deslizamiento, e incluso a una mutación, de estas representaciones? En caso afirmativo, la crisis mundial abierta en 2008, ¿ constituye realmente un giro o es simplemente el reflejo de un nuevo entorno ? Esbocemos algunas respuestas.

\section{Perímetros latinoamericanos y perímetros americanos}

13 El concepto "América Latina» plantea, de entrada, la necesidad de recurrir a conceptos complementarios. Es propio de los conjuntos geopolíticos variados y de las áreas culturales mestizas, ya que cuestiones como la diversidad cultural o la identidad no se dejan encerrar fácilmente dentro de las fronteras trazadas por la geografía. Además, la evolución de las disciplinas académicas propicia los acercamientos 
disciplinares que cambian la perspectiva de análisis y la forma de percibir la materia de estudio.

14 ¿ De qué América estamos hablando ? La noción de América ha sido monopolizada durante largo tiempo por los Estados Unidos, al igual que la de América Latina lo fue en la visión decimonónica de Europa. Dado que parece imponerse la idea de varias Américas, al menos desde el punto de vista geográfico, ¿podemos hablar de varias Américas Latinas ? Frente a este mosaico de situaciones nacionales bien diferenciadas pero que comparten determinismos geográficos y experiencias históricas más o menos similares, Marcel Niedergang (1962) se resuelve a hablar, en los años 60, de Américas Latinas. Por otro lado, ¿ hay que limitarse a los Estados del continente? ¿Cómo considerar los Estados insulares del Caribe ? La inclusión de Cuba o de la República Dominicana en América Latina no sorprende a nadie. ¿ Puede decirse lo mismo de Jamaica o de Trinidad y Tobago, e incluso de Haití? El léxico de las organizaciones internacionales refleja estas ambigüedades:la CEPAL (Comisión Económica para América Latina dentro de la ONU) reagrupa a los países situados al sur del Río Grande, incluyendo los del Caribe. Por el contrario, la Unión Europea ha optado por diferenciar y reunir al mismo tiempo a América Latina y al Caribe, tal y como reflejan las cumbres institucionalizadas entre ambos continentes ${ }^{4}$.

$¿$ Resulta útil recorrer la historia en este intento de clarificación de los perímetros latinoamericanos? Ciertamente, tras la independencia y hasta los años 80, España recurrió al concepto de Hispanoamérica (Rojas Mix, 1991 ; Herodote, 1990) para designar al conjunto de naciones surgidas del desmembramiento de su imperio colonial. Cabe señalar que Portugal, por su parte, no lanzó el término equivalente : Lusoamérica. En cambio, ambos países, unidos por su pertenencia a Europa, han ideado una nueva denominación : Iberoamérica. Impulsado principalmente por España a finales de los años 80, el perímetro iberoamericano tiene el mérito de incluir - a diferencia del concepto de Hispanoamérica-al gigante brasileño, un dato no menor si se piensa en la importancia que tiene Brasil en la estrategia de internacionalización de las empresas españolas, por tomar un ejemplo.

16 Y otra observación : ¿ cómo tratar a un México que, situado geográficamente en América del Norte, fue una pieza clave de la América española bajo la colonización y sigue siendo uno de los componentes esenciales del alma latinoamericana pese a orientar la mayor parte de su actividad económica hacia la América anglosajona (Pinot de Villechenon, 2010)?

17 La «materia latinoamericana » no es una materia inmóvil : se nutre de la historia, la geografía, los intercambios económicos, los lazos culturales, sin olvidar los tráficos (droga, armas) y los movimientos de población que, aún hoy, siguen moldeando sus contornos. Proyectada a escala del continente o del hemisferio (como se dice en las Américas), la «materia americana » tampoco resulta inmutable : ¿ cómo obviar la latinización que se está operando en Estados Unidos desde hace varias décadas bajo la presión de las migraciones ? ¿ O la erosión paulatina de la supremacía estadounidense que afecta el orden internacional y, también, continental ?

18 En este contexto en que los perímetros americanos están sujetos a cambios, ¿ sigue siendo pertinente hablar de América Latina? 


\section{8, ¿ un punto de inflexión?}

19 La segunda pregunta es : la crisis financiera de septiembre de 2008 y la crisis económica resultante, ¿ explican por sí solas las representaciones actuales de las Américas y de América Latina en particular? Dicho de otro modo, los distintos perímetros latinoamericanos de los que vamos a hablar, $¿$ han sido diseñados o rediseñados por la crisis?

Los observadores y políticos latinoamericanos coinciden en afirmar, de un lado, que dicha crisis, por una vez, no la han generado las economías del subcontinente, y de otro, que sus efectos han sido menos severos aquí que en otras zonas. Algunos van incluso más lejos : la crisis podría estar creando oportunidades para la región en su conjunto (Kourliandsky, 2010). Como recordaba hace muy poco el ex presidente del Gobierno español Felipe González, muy familiarizado con la realidad del subcontinente desde los años 80 , « el mundo ha cambiado radicalmente en los últimos 20 años y esta crisis es prueba de ello. El super Occidente, que representa el $17 \%$ de la población mundial, ha gastado lo que tendrá que pagar en los próximos veinte años, mientras que los llamados 'países emergentes' han ahorrado lo que van a poder comprar en los próximos veinte años $»^{5}$. Ello recuerda las palabras de un ex alto cargo del FMI que comparaba las potencias occidentales con un «club de países deudores». Más recientemente, las reformas operadas dentro del FMI para modificar el peso y la participación de los Estados en el capital de la organización, reflejan esta nueva situación ${ }^{6}$.

21 Por tanto, las causas de los cambios que se han producido en el espacio latinoamericano hay que buscarlas más allá de la crisis.

\section{¿Sigue siendo válido el perímetro latinoamericano?}

La denominación "América Latina », que data del siglo xIX y cuya historia ha sido analizada en más de una ocasión ${ }^{7}$, sigue teniendo pleno sentido hoy día. En efecto, América Latina sigue siendo un conjunto susceptible de ser estudiado como tal, y esto es aplicable sobre todo desde el punto de vista cultural. En Europa encontramos innumerables pruebas de esta percepción:instituciones culturales, espacios académicos y de investigación, acontecimientos artísticos y literarios... buen número de ellos hacen de América Latina su razón de ser o el objeto de su actividad.

El perímetro latinoamericano también sigue siendo apropiado para tratar temas políticos, económicos o sociológicos. Existen numerosas problemáticas que, de hecho, se abordan mejor desde una "perspectiva latinoamericana", algo que se explica a través de la historia : pasado común, condicionamientos similares, etc. América Latina es un perímetro de análisis tan justificado como pueda ser el Magreb, por ejemplo. Sin embargo, las iniciativas en materia de integración regional, así como las estrategias de respuesta de cada país a los desafíos globales, ponen de manifiesto una realidad menos homogénea, más compleja. 


\section{Los perímetros subregionales}

reciente. Algunos son casi contemporáneos a la Comunidad Europea, elevada a menudo a la categoría de modelo. Es el caso del Pacto Andino, creado en 1969 y rebautizado CAN ; del Mercado Común Centroamericano, fundado en 1960 y denominado SICA hoy día ; o de la Comunidad del Caribe, fundada en 1972. Por su parte, el Mercosur, primer tratado de integración del periodo posterior a la Guerra Fría, se crea en 1991.

bien la práctica de la integración ha permitido que los países latinoamericanos se ejerciten en la disciplina integracionista (búsqueda del consenso, formulación de una agenda común), hay que reconocer que, hasta finales de los años $80^{8}$, estos perímetros intra latinoamericanos no tenían cabida en las representaciones de los operadores exteriores, ya fueran actores políticos o inversores, ni tampoco en las de los agentes económicos y los ciudadanos de los países concernidos. Ya fuera en Bruselas, París o Madrid, en las relaciones con América Latina se dio prioridad durante mucho tiempo al perímetro estatal, como lo prueba el carácter primordial dado al diálogo bilateral, esto es, con cada Estado latinoamericano. Habrá que esperar los años 80 para que los perímetros subregionales andino o centroamericano, por poner sólo estos ejemplos, sean tomados en consideración por la Unión Europea.

\section{a) ¿ Mercosur o Cono Sur?}

El nacimiento del Mercosur en 1991 constituye un verdadero punto de inflexión. Se produce en un contexto de mundialización acelerada, en el que las empresas europeas se internacionalizan a gran escala y los países de la región aplican en sus políticas económicas los principios liberales conocidos con el nombre de Consenso de Washington. Contrariamente a lo que ocurrió en integraciones anteriores, los miembros fundadores (los presidentes argentino y brasileño de los años 80, Raúl Alfonsín y José Sarney, respectivamente) tuvieron ab initio la intención de favorecer no sólo el acercamiento político sino también la integración de los aparatos productivos de las economías del Mercosur.

En Europa, el Mercosur, percibido como un primo hermano de la Unión, suscitó un verdadero entusiasmo entre los operadores económicos. Puede afirmarse que la representación del Mercosur adquirió entonces una consistencia real fuera de sus fronteras, sobre todo en Europa. Desde los fabricantes de automóviles a los organizadores de ferias y salones, numerosos sectores económicos incorporaron el perímetro mercosuriano en su estrategia de desarrollo en América Latina.

No obstante, la representación geográficamente próxima del Cono Sur ${ }^{9}$ experimenta también un nuevo impulso en esa misma época, sobre todo en la primera mitad de la década. Dicha representación resulta funcional porque refleja la evolución que se estaba produciendo en aquel momento en el extremo meridional de América del Sur: Brasil no había iniciado aún el proceso de reformas estructurales puestas en marcha por Chile bajo la dictadura militar, y por Argentina, a partir de 1991. Dichas reformas serán emprendidas por el Gobierno de F.H. Cardoso a partir de 1994.

En 1996, el acercamiento de Chile al Mercosur en calidad de miembro asociado (estatuto que sigue teniendo actualmente) proyecta entre los europeos la esperanza de ver al país 
trasandino adherirse plenamente al Mercosur. Por consiguiente, el perímetro « Mercosur + Chile » tenderá a imponerse en Europa hasta finales de los años 1990.

Las dificultades dentro del Mercosur se agudizaron con la devaluación brasileña de 1999, confortando a Chile en su decisión de no adherirse plenamente a la unión aduanera. En consecuencia, Chile abogó ante Europa por la apertura de negociaciones Unión Europea - Chile, lo que concluyó como es sabido con la firma de un ambicioso acuerdo en 2002. Dicho acuerdo sacó a Chile de la zona de gravitación del Mercosur, según la representación de los europeos.

El estudio realizado por CERALE sobre la percepción que los inversores franceses tenían de Argentina en 2007-2009 es buena muestra del vínculo que existe entre representaciones estratégicas y perímetros funcionales. En este periodo, el Mercosur se muestra parcialmente sumido en sus dificultades, demasiado exiguo para un Brasil que ya no proyecta sus ambiciones en la escena regional sino mundial, y menos pertinente para los países miembros cuyas exportaciones se basan en las materias primas y se concentran en China. No es sorprendente que gran parte de las empresas entrevistadas (excluyendo a los fabricantes de automóviles) reconocieran no tomar en consideración este perímetro en su estrategia regional, mientras que, quince años antes, era una de las razones principales expuestas por los operadores económicos para explicar su desarrollo en América del Sur ${ }^{10}$.

Pese a la existencia del Mercosur, el perímetro Chile + Argentina siguió siendo pertinente en las representaciones europeas de los años 90, como muestran las misiones destinadas a promover este espacio geográfico para la internacionalización de las empresas europeas. Entre los aspectos que pueden explicar este hecho están los siguientes : Brasil, único país de habla portuguesa, aparece como un subcontinente en sí mismo por sus dimensiones territoriales y el tamaño de su mercado (Pinot de Villechenon, $2005: 476-477)$. La comunidad lingüística existente entre Chile y sus vecinos y el tamaño restringido de su mercado llevan a las misiones de prospección económica y comercial a definir un perímetro mayor que reúna a los dos países. Más allá del acuerdo firmado entre la Unión Europea y Chile, todavía hoy ciertos sectores de actividad como la promoción universitaria francesa en América Latina ${ }^{11}$, se sustentan en este perímetro.

El perímetro mercosuriano genera numerosas dudas hoy día, tanto en los círculos empresariales europeos como en los latinoamericanos. La ampliación del bloque está en marcha : adhesión de Venezuela y firma del Protocolo de Adhesión de Bolivia en 2012, solicitud de adhesión plena de Ecuador y solicitud de incorporación de Surinam como miembro asociado... Al mismo tiempo, en la Cumbre de Mendoza, en junio de 2012 y por primera vez en la historia del bloque, uno de sus miembros, Paraguay, ha sido suspendido tras la destitución del presidente Lugo. Si bien dichas ampliaciones traducen un verdadero interés de los vecinos sudamericanos por este espacio subregional dominado por Brasil y su inmenso mercado, cabe preguntarse acerca de la capacidad de sus miembros para garantizar el funcionamiento de una unión aduanera que existe hoy día a duras penas, habida cuenta de los obstáculos a los intercambios intrarregionales impuestos por los propios miembros fundadores. 


\section{b) América del Sur y UNASUR}

34 relatos de viajeros ilustres ${ }^{12} \mathrm{o}$ de las divisiones geográficas que pueden encontrarse en las grandes administraciones francesas o europeas, en las que es frecuente que exista una dirección para América del Sur, ¿ es funcional hoy día el perímetro de UNASUR, tanto para los sudamericanos como para los actores extrarregionales?

Si analizamos la historia de las representaciones políticas y económicas de este perímetro, vemos cómo, a finales de la década pasada, este espacio se instala progresivamente en la percepción estratégica de los responsables económicos ${ }^{13}$ primero, y políticos, después. El fenómeno puede explicarse por ser el interés por el espacio sudamericano inversamente proporcional al interés por el Mercosur. Si bien a principios de los años 90 el Mercosur había generado un elevado nivel de expectativas $\mathrm{y}$, consecuentemente, de inversiones - entre los socios europeos (ver más arriba), a partir de la crisis argentina de 2001, el bloque no logra enviar señales claras y coherentes a los inversores del exterior. El profundo cambio en las reglas de juego internacionales provocado por la irrupción de China, la tendencia al alza de los precios de los commodities, el pujante papel de Brasil en la escena internacional ${ }^{14} \mathrm{y}$ el dinamismo registrado por otros países sudamericanos como Colombia y Perú hicieron el resto. El Mercosur como bloque no alcanza a abarcar las nuevas dinámicas económicas de América del Sur lo que facilita la emergencia del perímetro sudamericano en las representaciones estratégicas de los actores regionales y extrazona. A ello se añade el acercamiento Mercosur-Comunidad Andina que, con la incorporación de Chile, la Guayana y Surinam, desemboca en la creación de la UNASUR en 2008. Hoy día, parece legítimo preguntarse sobre la consistencia de este nuevo perímetro sudamericano y sobre las representaciones que genera, tanto entre los latinoamericanos como entre los socios de fuera de la región.

La UNASUR es un perímetro funcional, en primer lugar, para los sudamericanos mismos. La historia reciente ha demostrado que en más de una ocasión ha permitido atenuar el conflicto persistente entre los presidentes Hugo Chávez y Alvaro Uribe. Las tensiones bilaterales surgidas tras las acusaciones de Colombia sobre la presencia de guerrilleros de las FARC en Venezuela y Ecuador también fueron tratadas en este foro. La UNASUR se convirtió también en un espacio donde manifestar la solidaridad sudamericana como ocurrió en septiembre de 2010 con Ecuador, cuando el presidente Correa denunció un intento de golpe de Estado. La UNASUR dio prueba de una unidad sin fisuras : convocó una reunión de urgencia para condenar los hechos y congregó en Quito a los ministros de asuntos exteriores de los países miembros para mostrar su solidaridad con el gobierno ecuatoriano. Se adoptó una declaración en la que se condenó enérgicamente el golpe de Estado y se anunció la pronta instauración de una " cláusula democrática »" ${ }^{15}$. Merece destacarse la rapidez y la unanimidad de la reacción tratándose de una región en la que los derrocamientos, logrados y frustrados, de gobiernos civiles permanecen aún en la memoria colectiva. En lo que se refiere a Brasil, un actor cuya percepción estratégica no puede ignorarse, este perímetro sudamericano le brinda un espacio donde ejercer un liderazgo regional amigable ${ }^{16}$.

Señalemos también que fue en este perímetro donde se creó, en marzo de 2009, el Consejo de Defensa sudamericano después de que Brasil hubiera intentado lanzarlo un año antes. Se trata del primer foro que reúne a los responsables de las Fuerzas Armadas 
de los doce países miembros con el objetivo declarado de promover la paz y desarrollar la cooperación militar entre sus miembros.

Esta iniciativa adquiere aún más relevancia cuando se recuerda que fue precisamente una cuestión militar lo que hizo que la UNASUR mostrara sus diferencias : la firma en 2009 por parte de Colombia de un acuerdo con Estados Unidos por el que se permitía al ejército estadounidense utilizar las bases militares colombianas. Venezuela, Ecuador y Bolivia mostraron su enérgica oposición, seguidos de Brasil y Argentina, mientras que Chile, Uruguay, Paraguay y Perú se desmarcaron anunciando que respetaban el acuerdo firmado por Colombia. También se ha abierto camino la idea de dotar a la UNASUR de un banco propio : el Banco del Sur. Se prevé que la entidad inicie sus operaciones a lo largo de 2013, tal y como acordaron los responsables de Finanzas de Argentina, Bolivia, Brasil, Ecuador y Venezuela.

El perímetro de la UNASUR resulta pertinente para los Estados miembros en la medida en que les permite gestionar por sí mismos las dificultades, los conflictos y los problemas que surgen dentro del perímetro. En el pasado, la integración latinoamericana ha mostrado que podía salir fortalecida de procesos guiados por el objetivo de articular una respuesta latinoamericana a las dificultades latinoamericanas. La construcción progresiva del Grupo de Río en los años 80 es ejemplo de ello : dicho grupo, surgido a partir del Grupo de Contadora y del Grupo de Apoyo ${ }^{17}$ en medio del proceso de paz centroamericano (Diálogo de San José), trabajó para alcanzar una solución latinoamericana al conflicto.

Desde este punto de vista, la capacidad de UNASUR para generar resultados concretos en beneficio de sus Estados miembros es real. No obstante, el panorama presenta algunas zonas de penumbra. Examinemos primero su consistencia institucional. El perímetro regional se institucionalizó en 2011, al entrar en vigor su tratado constitutivo tras reunir el número de ratificaciones necesarias. En virtud del mismo, la UNASUR se dotó de una carta orgánica, una sede (Quito) y una secretaría general. Sin embargo, el nombramiento en 2010 por parte de los Estados miembros del ex presidente argentino Néstor Kirchner-dirigente político poco propenso al juego diplomático y a la construcción de consenso - al frente de la secretaría general, puede interpretarse como una prueba de la importancia secundaria que los países miembros otorgaron a este organismo en sus inicios. Tras el fallecimiento repentino de N. Kirchner el 27 de noviembre de 2010, el venezolano Alí Rodríguez Araque, del entorno de Hugo Chávez, ha asumido el cargo de secretario general desde 2013.

41 En segundo lugar, la UNASUR se muestra menos eficaz cuando se trata de solucionar conflictos fuera de su perímetro, como ilustra la gestión de la crisis hondureña a partir de junio de 2009. El análisis que hicieron los gobiernos sudamericanos sobre la situación en Honduras no fue convergente y sus diferencias persistieron más allá del derrocamiento del gobierno de Manuel Zelaya, ya que el reconocimiento de los resultados del proceso electoral que en noviembre de 2009 llevó a Porfirio Lobo a la presidencia del país centroamericano no fue unánime dentro de la organización, ni tampoco la participación oficial del presidente Lobo en la Cumbre UE-ALC de Madrid en mayo de 2010 : mientras Colombia y Perú se mostraron favorables, el resto se opuso.

En tercer lugar, algunos miembros de la organización (Venezuela, Ecuador y Bolivia) lo son también de ALBA, la Alianza Bolivariana para las Américas. Ésta no está circunscrita a un perímetro geográfico preciso - como sí lo está UNASUR - sino que es el resultado de una cercanía ideológica cuyo eje central es el antiimperialismo, por no decir el 
sentimiento anti-EEUU. Además de los tres países citados, la Alianza agrupa a Antigua y Barbuda, Cuba, Dominica, San Vicente y las Granadinas y Nicaragua. Podemos por tanto preguntarnos sobre los riesgos de esta superposición: ¿Pérdida de energías? ¿Canibalización? ¿Intereses contradictorios? Estas preguntas enlazan con la cuestión del liderazgo ejercido por algunos dirigentes latinoamericanos : por un lado, un eje en torno a Cuba-Venezuela (el ALBA) unidos por un antiamericanismo visceral e intereses diversos (necesidades energéticas, cooperación técnica, servicios, educación, etc.) que permiten al régimen cubano sobrevivir y al gobierno chavista ejercer su influencia en el Caribe vecino; por otro, un espacio - la UNASUR - donde Brasil logra asentar su liderazgo regional y moderar, con el respaldo de Argentina, Chile y otros vecinos, la vehemencia de sus socios más antinorteamericanos. La historia reciente ha ofrecido varios ejemplos de la capacidad del presidente Lula para reducir dentro de la UNASUR la belicosidad de algunos de sus vecinos y evitar que el espacio unasuriano acabe convirtiéndose en una caja de resonancia del « antiimperialismo $»^{18}$. La desaparición de Hugo Chávez en marzo de 2013 abre una serie de interrogantes sobre la vitalidad de ALBA, dado que desde entonces no se ha encontrado sustituto a su liderazgo dentro de este perímetro.

Perfilada desde finales de 2001, ALBA nació de un antagonismo explícito hacia la potencia estadounidense : lleva el antiamericanismo en sus genes. Es, en cierto modo, una anti-ALCA ${ }^{19}$. Pero no puede decirse lo mismo de la UNASUR. Desde esta perspectiva, la doble pertenencia de algunos miembros a uno y otro esquema que acabamos de plantear como una fuente de incertidumbre puede convertirse en una ventaja para la UNASUR. Ciertamente, los cimientos de la UNASUR no son ideológicos y la organización se muestra como la convergencia progresiva y natural del MERCOSUR y de la CAN. Su perímetro está trazado en términos simples por la geografía continental que se impone al sur del Canal de Panamá. Como en el perímetro de la Europa comunitaria, la promiscuidad territorial es evidente (i.e. se traduce en el espacio físico) y el vecindario se presta fácilmente a los más diversos acercamientos: intercambios comerciales, infraestructuras comunes, circulación de personas, etc.

En su corta vida, la UNASUR se ha dedicado más bien a tratar y resolver tensiones internas y a reforzar los valores de la democracia, pese a que las derivas autoritarias de algunos gobiernos sudamericanos han obligado a los dirigentes a mostrarse habilidosos a la hora de elaborar los textos y las declaraciones que han ido marcando regularmente las cumbres. El hecho de no haber abordado en profundidad la cuestión de la liberalización del comercio entre sus miembros, en cierto modo, ha salvado a la organización de la crispación que caracteriza las negociaciones comerciales y, sin duda, ha facilitado la construcción de una expresión política consensual. Desde este punto de vista, la organización tiene posibilidades de perdurar siempre y cuando resulte - como decíamos - funcional para con los intereses de sus miembros y, en primer lugar, de Brasil. La presidenta brasileña no ha modificado sustancialmente las percepciones brasileñas de la UNASUR. Si bien al inicio de su mandato podía esperarse un nuevo impulso en favor del MERCOSUR, las orientaciones proteccionistas de la política económica argentina han bloqueado desde entonces cualquier intento de profundización de aquel. Dado que el perímetro mercosuriano está contenido en el de la UNASUR, los bloqueos en uno y las muestras de solidaridad política en la otra no pueden poner trabas al papel de actor global asumido por Brasil. 

perímetro que, a fin de cuentas, no es contrario a sus intereses. El espacio sudamericano aparece alejado de los principales focos de tensión del planeta y la UNASUR demuestra no sólo su capacidad para contener en su seno a los gobiernos más díscolos, sino también su apego a la idea de hacer de este espacio del planeta un espacio de paz. Es cierto que las fluidas relaciones de Hugo Chávez y Evo Morales con el presidente Ahmadineyad, mientras Occidente sospecha que el régimen iraní podría estar desarrollando armas nucleares, no van en ese sentido. Sin embargo, dichas relaciones son sólo cosa de algunos gobiernos y no se enmarcan en una iniciativa « regional ». Con respecto a la compra de armamento por parte de distintos miembros en los últimos años, ya sea a Rusia, Francia o Estados Unidos, ello no basta para considerar al espacio sudamericano como un espacio fuertemente militarizado dado el retraso en la materia que ha acumulado la región en su conjunto en estos veinte últimos años ${ }^{20}$.

Teniendo en cuenta los desafíos ante los que el terrorismo global ha puesto a Occidente, esta contribución positiva de UNASUR al equilibrio mundial es bien recibida.

\section{c) La Alianza del Pacífico}

Formada por México, Colombia, Perú y Chile, la Alianza fue creada formalmente en la Cumbre de Antofagasta en junio de 2012, tras una serie de encuentros de los jefes de Estado. Cabe destacar la participación de México que, sin tener fronteras físicas con el resto de miembros, sí comparte las mismas orientaciones económicas que sus socios en favor de la apertura comercial y la liberalización de los intercambios. Guiados en un principio por el deseo de optimizar sus estrategias comerciales hacia Asia, los países miembros acabaron progresivamente definiendo otras esferas de colaboración : libre circulación de bienes, servicios, capitales y personas entre miembros y voluntad de trabajar en favor del desarrollo económico y social dentro del espacio latinoamericano. Se estableció una presidencia pro témpore y se definieron reglas sobre la adhesión de los nuevos miembros que empezaron a manifestarse ${ }^{21}$. Merece destacarse la voluntad de sustentar el proceso en la dinámica de los negocios: se estableció un Consejo Empresarial y la Cumbre de 2013 dio lugar a un encuentro homónimo. Recordemos también que varios países que se han unido al proyecto en calidad de observadores asistieron a la Cumbre de Cali en mayo de $2013^{22}$.

Los fundadores tienen en común el hecho de aplicar una política económica y comercial abierta. En 2012 registraron tasas de crecimiento bastante superiores a las del resto de América Latina. La Alianza es seguida con interés por el gigante brasileño. En efecto, el MERCOSUR ha perdido mucho de su dinamismo comercial en estos últimos años y la locomotora brasileña comienza a frenar (menos de $1 \%$ de crecimiento en 2012). ¿ Acabaremos viendo una nueva línea divisoria entre una Alianza del Pacífico dinámica, volcada hacia Asia, y un Mercosur cada vez más trabado desde el punto de vista comercial ? Si bien resulta prematuro zanjar esta cuestión, la presencia, junto a los 
países miembros, de jefes de gobierno de una decena de países americanos y de otros continentes, ha sido resaltada por la prensa internacional, dado que más de una cumbre latinoamericana, iberoamericana y euro-latinoamericana no ha logrado reunir a la totalidad de sus miembros. Esta participación no deja de resultar auspiciosa en esta etapa del proceso y traduce una percepción positiva del mismo por los actores regionales y extrazona.

\section{Vuelta a « la región » : ¿ una OEA sin los vecinos del norte?}

¿Qué decir, por último, de la recién estrenada Comunidad de Estados Latinoamericanos y Caribeños $^{23}$ (CELAC) proclamada en febrero de 2010 en México al término de la "Cumbre de la Unidad", como espacio regional que reúne a todos los Estados americanos (treinta y tres) excepto Canadá y Estados Unidos? La iniciativa dio lugar, durante la Cumbre de Caracas del 3 de diciembre de 2011 presidida por Hugo Chávez, a una Declaración, un Plan de Acción, así como un documento titulado " Procedimientos para el funcionamiento orgánico de la CELAC» que hacía las veces de carta constitutiva $^{24}$. La CELAC no pone en tela de juicio la existencia de la UNASUR ni del MERCOSUR. Apadrinada por el presidente bolivariano Hugo Chávez, aparece como « una OEA con Cuba y sin Estados Unidos ni Canadá » y se presenta como un mecanismo de concertación política y de cooperación. Sin sede permanente, la Comunidad se articula en torno a una presidencia pro témpore - respaldada por una troika y encuentros ministeriales - y reuniones de presidentes. Con motivo de la Cumbre eurolatinoamericana de Santiago de enero de 2013, la CELAC aprovechó para celebrar su propia cumbre y la presidencia pro témpore fue transferida de Chile a Cuba.

51 Pese a que carecemos de perspectiva para valorar su pertinencia, este nuevo perímetro está destinado a representar, de ahora en adelante, al conjunto de América Latina y el Caribe en las grandes citas que movilizan a otros bloques regionales y a garantizar el diálogo con otros actores intergubernamentales y organismos internacionales. Por ello, la CELAC asumirá a partir de ahora el diálogo institucionalizado en 1999 entre la Unión Europea y el Grupo de Río sustituyendo a este último, que deja de funcionar como tal pero cuyo acervo (declaraciones y comunicados de todo tipo) se incorpora a la CELAC. La Cumbre de Santiago, séptimo encuentro bicontinental, constituye así la primera Cumbre EU-CELAC.

En este punto, cabe destacar también el acercamiento Brasil-México anunciado en México en 2010, pues una alianza entre las dos mayores economías de América Latina supondría, vía un aumento de los intercambios, el regreso de México al espacio latinoamericano que descuidó en los años 90 en beneficio de América del Norte (Pinot de Villechenon, 2010). Además, permitiría contrarrestar el liderazgo brasileño que domina ampliamente hoy día. El hecho de que en septiembre de 2012, previamente a su toma de posesión, el presidente Peña Nieto decidiera visitar a sus homólogos de Guatemala, Colombia, Brasil, Chile, Argentina y Perú parece anunciar un cambio de orientación en provecho de los vecinos del Sur. 


\section{A modo de conclusión} emergencia de Brasil como potencia regional ; por otro, estaríamos asistiendo al final de un largo capítulo de las relaciones internacionales latinoamericanas, abierto tras la independencia, en el transcurso del cual Europa y Estados Unidos han sido los interlocutores privilegiados de los gobiernos latinoamericanos y los ejes en torno a los cuales dichos gobiernos han construido gran parte de su política exterior. ¿ Estará América Latina cortando el cordón umbilical que la une a sus parientes de Occidente?

\section{BIBLIOGRAPHIE}

Aramburu, Felipe et Christian Preda Salem, Étude sur les perceptions de l'environnement des affaires en Argentine, tesis de maestria en Management, CERALE, ESCP- Europe, junio 2010.

CELAC, Declaración de Caracas « En el Bicentenario de la Lucha por la Independencia Hacia el camino de Nuestros Libertadores ». Disponible en línea : http://www.latinreporters.com/ amlatCelacDeclaracionCaracas03122011.pdf.

CELAC, Comunidad de Estados Latinoamericanos y Caribeños (CELAC) Procedimientos para el funcionamiento orgánico de la CELAC. Disponible en linea : http://www.latinreporters.com/ amlatCelacProcedimientos03122011.pdf.

CELAC, Plan de Acción de Caracas 2012. Disponible en línea : http://www.latinreporters.com/ amlatCelacPlanAccionCaracas2012.pdf.

Girault, Christian (dir.), Intégrations en Amérique du Sud, Paris, Presses Sorbonne nouvelle, 2009.

Hérodote, De Gibraltar à Panama, nº 57, La Découverte, $2^{\text {ème }}$ trimestre 1990.

Kourliandsky, Jean-Jacques, « La crise internationale porteuse de nouvelles donnes », in Pascal Boniface (dir.), L’Année stratégique 2011, IRIS, éd. Armand Colin, 2010.

Lacoste, Yves (dir.), « Représentations géopolitiques », in Dictionnaire de géopolitique, Paris, Flammarion, 1995. 
La Nación, «El liderazgo de Brasil », editorial La Nación, 7 de mayo de 2009. Disponible en línea : http://www.lanacion.com.ar/1125178-el-liderazgo-de-brasil.

López, Diego et alii, « La perception des investisseurs français de l'environnement des affaires en Argentine. Enquête CERALE 2006-2007 », in Florence Pinot de Villechenon, L'Argentine terre d'investissement ?, Paris, L'Harmattan, 2008.

Martinière, Guy, « Interrogation. La latinité de l'Amérique », in Le Monde diplomatique, juillet 1982. Monclaire, Stéphane, «Le Brésil et la quête d'un nouveau statut international », in Questions internationales, La Documentation française, IHEAL et CREDAL, $\mathrm{n}^{\circ} 18$, mars-avril, 2006, Paris.

Musset, Alain (dir.), Géopolitique des Amériques, Paris, Nathan, 2009.

Niedergang, Marcel, Les 20 Amériques latines, Paris, Plon, 1962.

Pinot de Villechenon, Florence, « La latinidad, una cuestión de afinidad cultural en las relaciones eurolatinoamericanas ", in Koronís. Homenaje a Carlos Ronchi March, Instituto de Filología Clásica de la Universidad de Buenos Aires, 2003.

Pinot de Villechenon, Florence, Des représentations à la mise en œuvre d'une stratégie de coopération avec un pays en voie de développement. Le cas de la coopération française avec l'Argentine de 1985 à nos jours, Tesis doctoral Sociedades occidentales - opción Historia, Universidad Paris 7 - Denis Diderot, UFR Géografia, historia y ciencias sociales, 2005.

Pinot de Villechenon, Florence, « Las estrategias comunitarias hacia América Latina. De la complejidad de articular la macrodiplomacia con la microdiplomacia y las esferas nacionales con la esfera comunitaria », comunicación escrita presentada en $\mathrm{el} \mathrm{V}^{\circ}$ Congreso Europeo CEISAL, Las relaciones triangulares entre Europa y las Américas en el siglo XXI : expectativas y desafíos, Universidad Libre de Bruselas, 11-14 de abril de 2007.

Pinot de Villechenon, Florence, «Le Mexique est-il toujours latino-américain ? ", in Problèmes économiques, La Documentation française, $n^{\circ} 2999,7$ juillet 2010.

Pommier, Edouard, « Notes sur l'histoire de l'idée latine en France », in Union latine, 2004.

Rouquié, Alain, Le Brésil au XXI ème siècle. Naissance d'un nouveau grand, Fayard, 2006.

Rojas Mix, Miguel, Los cien nombres de América. Eso que descubrió Colón, Editorial Lumen, 1991.

Rosière, Stéphane, Géographie politique et géopolitique. Une grammaire de l'espace politique, Paris, Ellipses, 2003.

Tokatlian, Juan Gabriel, « Estados Unidos persiste en el error », in La Nación, 16 de noviembre de 2010. Disponible en línea : http://www.lanacion.com.ar/1325179-estados-unidos-persiste-en-elerror

\section{NOTES}

1. Ver Pinot de Villechenon (2010 : 470-471, 546-547 ; 2007).

2. Ver Lacoste (1995: 1267-1268).

3. Ibid., p. 1268-1269.

4. Hasta la Cumbre de Santiago de enero de 2013, la denominación utilizada es Cumbre Unión Europea-América Latina y Caribe

5. Entrevista publicada en el sitio web del diario colombiano El Tiempo, el 19 de septiembre de 2010. 
6. Los países emergentes van a tener más peso dentro del FMI : se prevé que el $5 \%$ de las partes de esta institución cambien de mano después de una primera reasignación de 2,7 \% decidida en 2008.

7. Para un enfoque muy completo sobre la arqueología del concepto, véase Pommier (2004:7). Véase también Pinot de Villechenon (2003 : 395-409), Martinière (1982) y Musset (2009).

8. El « Diálogo de San José ", iniciado en 1984 y en el que participaron la Comunidad Europea y España, marca el principio de la toma en consideración por parte de Europa de la realidad regional latinoamericana.

9. Véase definición de Yves Lacoste, op. cit., p. 465 a: «Esta denominación de carácter geoestratégico que designa la parte más meridional de América del Sur hace referencia a la forma que tiene América Austral y engloba dos Estados principalmente:Chile y Argentina, a los que pueden añadirse dos Estados tapón, Uruguay y Paraguay. A veces puede incluirse el sur de Brasil cuando la expresión ‘Cono Sur' se utiliza en el contexto del Mercosur ».

10. Véase Diego López et alii (2008 : 208-209), y Aramburu y Preda Salem (2010).

11. Los salones organizados por Campus France reúnen a ambos países en el seno de una misma manifestación.

12. Véase por ejemplo la obra de Georges Clémenceau, Notes de voyage dans l'Amérique du Sud: Argentine, Uruguay, Brésil, Paris, Utz, 1991.

13. El Banco Mundial, el CNPF de la época (hoy MEDEF), la COFACE, etc. se decantan, en el marco de diversos seminarios, por la denominación « América del Sur » y no por « América Latina ».

14. Véase Monclaire (2006) y Rouquié (2006).

15. La "cláusula democrática», en virtud de la cual cualquier ataque a las instituciones democráticas de un país puede terminar con su exclusión de los tratados internacionales correspondientes, se introdujo en los años 80 en los Tratados de Amistad y Cooperación suscritos por Italia y España con las naciones latinoamericanas. Seguidamente, dicha cláusula fue incorporada a los acuerdos llamados « de tercera generación » que Bruselas firmó con la mayoría de países latinoamericanos. También la encontramos en el Acuerdo Interregional firmado entre el Mercosur y la UE en 1995, y dentro del Mercosur como tal. Resultó rápidamente efectiva cuando Paraguay se vio sacudido por una serie de intentos de desestabilización por parte de las fuerzas armadas, en 1996, y posteriormente, por el asesinato, el 23 de marzo de 1999, del vicepresidente Argaña y el levantamiento militar de los días 18 y 19 de mayo de 2000 que amenazaron con derrocar al presidente L. González Macchi.

16. A título de ejemplo, el presidente Lula se ofreció actuar como mediador entre Caracas y Washington en la Cumbre de las Américas de Trinidad y Tobago de abril de 2009. Señalemos además que Brasil representó en esa cumbre al gobierno cubano, gran excluido de este foro, a pesar de que la proximidad del gobierno cubano con Hugo Chávez podría haber llevado a la isla a confiar a Venezuela su representación (La Nación, 2009).

17. El Grupo de Contadora englobaba a México, Colombia, Venezuela y Panamá. Rápidamente y siempre en torno a la cuestión centroamericana, Argentina, Brasil, Uruguay y Perú constituyeron un Grupo de Apoyo. En 1986, ambos adoptaron el nombre de Grupo de Río al que terminaron por adherirse Chile, Ecuador y los demás países de la región, hasta representar a casi todos los Estados latinoamericanos.

18. Fue el caso del gobierno de Evo Morales que en 2008 tuvo que enfrentarse a los prefectos opositores, y de Colombia, que en 2009 firmó el ya mencionado acuerdo con Estados Unidos para permitir el acceso de las tropas y los proveedores estadounidenses a siete bases militares colombianas. En la actualidad, este acuerdo está suspendido tras una decisión de la Corte Constitucional colombiana que estima necesario someterlo a la aprobación del Parlamento. En ambos casos, Brasil logró evitar que en las declaraciones finales se añadiera una condena al gobierno de Barak Obama por « injerencia », como quería Hugo Chávez. 
19. Área de Libre Comercio de las Américas cuyo proyecto fue lanzado en 1991, a iniciativa de George Bush, y reconducido bajo el mandato de Bill Clinton y George W. Bush, para acabar siendo enterrado tras la IV Cumbre de las Américas celebrada en Mar del Plata en 2005.

20. Las alteraciones del orden democrático producidas en Honduras en 2009 y en Ecuador en 2010, el aumento del gasto militar en Venezuela, Colombia, Brasil y Chile, la creciente participación del ejército en la lucha contra la droga en México y Centroamérica, y las tensiones entre regiones fronterizas de Colombia y Venezuela, Perú y Chile, y Nicaragua y Costa Rica son la prueba, según Juan Gabriel Tokatlian, de que el militarismo sigue latente en la región (Tolkatlian, 2010).

21. Costa Rica, Guatemala y Panamá.

22. Costa Rica, Panamá, Guatemala, Uruguay, España, Japón, Australia, Nueva Zelanda y Canadá.

23. Comunidad de Estados Latinoamericanos y Caribeños.

24. Véanse documentos CELAC.

\section{RÉSUMÉS}

En utilisant les concepts de périmètre et de représentation cet article explore les récentes évolutions constatées sur le continent américain en matière d'intégration et en analyse les perceptions tant en Europe que dans les Amériques. Après avoir mesuré la portée des différents schémas d'intégration actuellement en vigueur - à l'échelle continentale, régionale et sousrégionale - et leur pertinence pour les pays membres, l'article s'interroge sur les causes de ces changements. Sur fond de crise, le réarrangement de la scène internationale contemporaine et l'émergence de nouveaux leaderships se substituant aux plus traditionnels du $\mathrm{XX}^{\text {ème }}$ siècle apparaissent comme étant à l'origine de ces changements.

A partir de los conceptos de " perímetro » y de " representación », el artículo explora las recientes evoluciones constatadas en el continente americano en materia de integración analizando las percepciones que de ellas se tiene en las Américas y en Europa. Tras medir el alcance de los diferentes esquemas de integración hoy vigentes - en la esfera hemisférica, regional y subregional - y su pertinencia para los países miembros, el artículo se interroga sobre las causas de dichos cambios. Con la crisis como trasfondo, el reacomodamiento de la escena internacional contemporánea y la emergencia de nuevos liderazgos que desplazan los tradicionales del siglo XX, aparecen como los principales causantes.

Based on the concepts of " perimeter " and " representation ", this paper explores the recent attempts of the American continent at integration, and analyzes how these changes are perceived by Europe and the Americas. After measuring the extent of the different integration schemes now in force - in the hemispheric, regional and sub-regional areas - and its relevance to member countries, the article questions the causes behind such changes. The rearrangement of the contemporary international scene and the emergence of new leaderships that displaced traditional $\mathrm{XX}^{\text {th }}$ century ones, appear to be responsible for such changes. 


\section{INDEX}

Keywords : regional integration, geopolitical representations, Mercosur, UNASUR, CELAC, ALBA, Pacific Alliance

Palabras claves : integración regional, representaciones geopolíticas, Mercosur, UNASUR, CELAC, ALBA, Alianza del Pacífico

Mots-clés : intégration régionale, représentations géopolitiques, Mercosur, UNASUR, CELAC, ALBA, Alliance du Pacifique

\section{AUTEUR}

\section{FLORENCE PINOT DE VILLECHENON}

Florence Pinot de Villechenon es profesora asociada en ESCP-Europe, donde coordina la cooperación académica con América Latina y dirige el CERALE (Centro de Estudios e Investigación América Latina-Europa). Egresada de la Universidad de Buenos Aires y de la Universidad Paris IVSorbonne, obtuvo su doctorado en la Universidad Paris VII. Sus trabajos de investigación se centran en la política latinoamericana de la UE y de los países miembros, las relaciones EuropaAmérica Latina, las estrategias de internacionalización de las empresas europeas particularmente las PyMES - en América Latina y la gestión de grandes proyectos culturales internacionales. Florence Pinot de Villechenon también imparte clases en el IHEAL y trabaja como experta en cooperación académica para los ministerios franceses de Asuntos Exteriores y de Educación. Es miembro de la Chambre du Brésil en Francia. Entre sus publicaciones figuran : «Cooperación descentralizada Europa-América Latina : contribuciones de la política de cooperación comunitaria a la consolidación de la democracia en Latinoamérica », Política pública y democracia en América Latina, F. Maríñez y V. Garza Cantú (ed.), Porrúa, 2009 ; L'Argentine, terre d'investissement ?, l'Harmattan, Paris, 2008 (dir.) ; « La latinidad : una cuestión de afinidad cultural en las relaciones eurolatinoamericanas ", Homenaje a Carlos A. Ronchi March, Universidad de Buenos Aires, 2003 ; Fêtes géantes. Les expositions universelles pour quoi faire?, Autrement, coll. Essais, 2000. pinotatescpeurope.eu 